\title{
ASSESSMENT OF NURSES PRACTICE ABOUT HEMODIALYSIS IN PORT-SAID CITY
}

Prof. Dr. Nabila Ahmed Bedier, Prof. Dr. Hashem M. Rashwan, Dr. Sanaa AbdElazim Ibrahim, Dr. Eman Saleh Shahin, Hayat Mohamed Ahmed Professor of Medical Surgical Nursing, Faculty of Nursing -Alexandria University, Chariman of Urology Dept, Faculty of Medicine-Suez Canal University, Assis Prof of Nursing Administration, Faculty of Nursing- Port Said University, Assis Prof of Nursing Medical Surgical, Faculty of Nursing- Port Said University, Lecturer of Medical Surgical Nursing ,Faculty of Nursing - Port Said University

\begin{abstract}
End-stage renal disease (ESRD) has become a public health concern worldwide as the total number of ESRD patients requiring renal replacement therapy has been growing dramatically. In Egypt, there is an increase in prevalence and incidence of ESRD exerting a great burden on the health system. Moreover, in Egypt there is insufficient information about the quality of nursing care of hemodialysis patients. The study aims to assess nurses' performances for patient undergoing hemodialysis. The study Question: what is the level of nurses performance for patient undergoing hemodialysis. Descriptive design was used in the current study. The present study was carried out in hemodialysis units in Port- Said general hospital, El-Mabara hospital and Port-Fouad general hospital in Port- Said city. The sample of this study consisted of all (fifty three) nurses who were assigned to provide direct care for patients undergoing hemodialysis. The data were collected using. Tool I: demographic data, Tool II: Nurses' practice sheet. Results: (1.8\%) of studied nurses have adequate $(60 \%+)$ performance related to nursing care for patients undergoing hemodialysis. Conclusion: Almost all nurses working in the hemodialysis units had total inadequate total performance. Recommended, Providing the working nurses with continuing education and in-service education training program about hemodialysis and its management including the standards of nursing care pre, during and post.
\end{abstract}

Key words: ASSESSMENT, NURSSES, PRACTICE, HEMODIALYSIS 


\section{INTRODUCTION}

Renal failure is a condition in which the kidneys fail to remove metabolic endproducts from the blood and regulate the fluid, electrolyte, and $\mathrm{pH}$ balance of the extracellular fluids. The underlying cause may be renal disease, systemic disease, or urologic defects of non renal origin. Renal failure is classified as acute or chronic. (Dewit \& Kumagia, 2013).

According to Zahran (2011) End-stage renal disease (ESRD) has become a public health concern worldwide as the total number of ESRD patients requiring renal replacement therapy has been growing dramatically. Chronic kidney disease (CKD) is at least 3-4 times more frequent in Africa than in developed countries. Patient registry and statistical evaluation of patients with ESRD are useful to clarify the characteristics of ESRD patients and dialysis therapy, as well as the complications or results based on scientific evidence, to improve the quality of dialysis therapy. According to the United States Renal Data System annual report (2011) (USRDS) the prevalence of ESRD varies worldwide, it can be high, as in Taiwan 2447 patients per million populations (pmp), Japan 2205 pmp, and United States $1811 \mathrm{pmp}$ and it can be low as in Philippines 110 pmp, Bangladesh 140 pmp and Russia 173 pmp. (Zahran, 2011).

Therefore the use of renal replacement therapy becomes necessary when the kidney can no longer be able to remove wastes, maintain electrolytes, and regulate fluid balance. This can occur rapidly or over a long period of time and there for the need for replacement therapy can be acute or chronic. The main renal replacement therapies include the various types of dialysis such as (hemodialysis \& peritoneal dialysis) in addition to kidney transplantation. (Dewit \& Kumagia, 2013).

Hemodialysis is the most common renal replacement therapy for renal failure. Dialysis is used to remove excess fluids and waste products and restores chemical and electrolytes balance. Hemodialysis involves passing patient's blood through an artificial semipermeable membrane (dialyzer) to perform the filtering and excretion of waste products. (Dewit \& Kumagia, 2013). 
Nephrology nurses can lead the way to implementing numerous proactive interventions before, during، and post hemodialysis because they often have more contact with patients than other clinical personnel and are in an ideal position to optimize assessment, management, and monitoring of clinical issues likely to affect patients on dialysis, including anemia, malnutrition, inflammation, vascular accessrelated infection, and volume status. They also serve integral roles in minimizing risk for medication- related issues by reconciling medication lists and improving discharge documentation and practices. (Castner, 2011).

Nursing role in hemodialysis systems include, cleaning and disinfection of dialysis equipments, developing preventative maintenance schedules for all dialysis equipments, documenting all dialysis equipments, maintaining emergency equipments in proper working order for immediate use, performing electrical leakage tests on all dialysis equipments; verifying blood dialysate flow rates and management of treatment such as adjust blood pump settings and pressure monitors to maintain safe and efficient dialysis per order of physician, They adjust fluid removal according to established protocols, administer local anesthetics according to established protocols, administer anticoagulants to patient, alter dialyzing fluid, apply pressure to cannulation sites after removal of cannulation needle, apply dressings to cannulation sites, cannulate, clean and dress access site using appropriate techniques, collect blood samples, monitor the dialyzer delivery system continuously during treatment and remove needles after termination of treatment (Ignatavicius \& Workman, 2010).

Hemodialysis is the most common renal replacement therapy for renal failure in hospital practice. Inappropriate management hemodialysis may lead a lot of complications due to bad nursing intervention for patients undergoing hemodialysis. Moreover hemodialysis patients are vulnerable to complications before, during and after treatment. Therefore, nursing intervention has a great impact on reducing risk of potential complications and promoting health in the presence of end stage renal disease (ESRD).

\section{AIM OF STUDY:}

Assessment of nurses' performance for patients undergoing maintenance hemodialysis

\section{Research questions:}

What are the nurses' performances about hemodialysis? 


\section{SUBJECT AND METHODS:}

\section{Design}

The study is an exploratory study investigated the actual performance of nurses' care for patients undergoing hemodialysis.

\section{Sample:}

The subjects of the study were a convenient sample covered fifty three nurse.

\section{Study Tool}

The tool used in this study was Nurses' performance checklist. This tool was developed by the researcher after reviewing the related literature to assess the actual performance of nurses who were providing care for patient undergoing hemodialysis. It included two parts.

\section{Part A: Socio-demographic Data:}

it included items related to socio- demographic characteristics of the studied nurses as their names, ages, educational levels, years of experience .

Part B: It included 22 essential procedures checklists related to the basic nursing competencies which covered the following items:

1. Assessment of patient's condition on admission.

2.Protecting patient from accident and injury.

3.Providing the physical needs and comfort.

4. Attention to the patient's privacy and civil rights.

5. Attention to the need for psychological and emotional well-being.

6.Preparing equipment and supplies.

7.Protective personal equipments as: Wearing masks, Wearing the gown and Wearing sterile gloves.

8. Performing hand hygiene (hand washing).

9. Assembling and setting up hemodialysis machine.

10. Evaluated and preparation the vascular access.

11. Initiating hemodialysis treatment.

12. Monitoring during hemodialysis.

13. Termination of hemodialysis set.

14. Removing masks.

15. Removing gown.

16. Removing gloves.

17. Obtaining blood sample.

18. Handling sharps.

19. Preparing of dressing package.

20. Preparing the crush cart.

21. Prepare dressing cart.

22. Responding to emergencies during hemodialysis. 
Performance scoring system: The items observed be done were scored " 1 " and the items not done were scored " 0 ". For each area, the scores of the items were summed-up and the total divided by the number of the items, giving a mean score for the part. These scores were converted into a percent score, and means and standard deviations were computed. The practice was considered adequate if the percent score was $60 \%$ or more and inadequate if less than $60 \%$.

\section{Validity and reliability}

The Tool of the study was tested for content validity by experts in the field of the study and necessary modifications was done; as some items were omitted from the performance checklists; such as repeated some point as hand washing that was omitted from some procedures. Some procedures were rearranged as assessment of the patient and preparation of machine and language were reviewed and corrected.

\section{Pilot study:}

A Pilot study was done on a sample of $10 \%$ of nurses in order to test the clarity, feasibility and reliability of the study tool.

\section{Methods of data collection:}

Data collection for assessment of actual nurses' performance were done by the researcher and other nursing instructor which had at least 3 years experienced working in hemodialysis unit. Assistant observer started after explaining different checklist steps to the them and training each observer on this checklist as follows:

-An approval was obtained from the chairman as well as head nurse of the hemodialysis unit after explanation of the aim and nature of the study before data collection. Studied nurses' (group two) were not aware that they were being observed to achieve objectivity in data collection.

- Appraisal of nurses' performance was done by the researcher while nurses provide direct care for hemodialysis patients.

\section{RESULTS}

Table (1) shows the characteristics of nurses providing direct care for patients undergoing hemodialysis. Regarding to age the majority of the studied nurses were in the age group 20-59 years old with the mean \pm SD of (31.2 \pm 9.3$)$. It can be seen that as regard to working setting, most of the studied nurses (60.3\%) in Port- Said general hospital. Concerning qualification $(92.6 \%)$ of the total studied nurses had diploma degree. In relation to years of experience most of them had 5years and more, while $(43.4 \%)$ of all studied nurses had previous training programs related to hemodialysis and $(5.7 \%)$ of them worked abroad. 
Table (2) Shows hemodialysis nurses total actual performance as regards hemodialysis standards of nursing care. It can be observed that $(1.8 \%)$ of studied nurses have adequate $(60 \%+)$ performance related to personal grooming of nurse, preparing equipment and supplies, protecting patient from accident/injury, attention to patient physical needs and comfort, preparing machine, evaluating vascular access, initiating hemodialysis treatment, termination of hemodialysis set for patient, termination of hemodialysis set for dialysis machine, termination of hemodialysis set for environment, removing mask, obtaining blood sample, infection control measures and response to emergencies during hemodialysis: patient response to hypotension 
Table (I):: Characteristics of nurses providing direct care for patients undergoing hemodialysis.

\begin{tabular}{|c|c|c|}
\hline \multirow[t]{2}{*}{$\begin{array}{l}\text { Characteristics of hemodialysis nurses providing } \\
\text { direct care for patients undergoing hemodialysis }\end{array}$} & \multicolumn{2}{|c|}{$\begin{array}{l}\text { Nurses } \\
(\mathbf{n}=53)\end{array}$} \\
\hline & No & $\%$ \\
\hline \multicolumn{3}{|l|}{ Age:(years) } \\
\hline$<30$ & 30 & 56.6 \\
\hline $30+$ & 23 & 43.4 \\
\hline Range of age & \multicolumn{2}{|c|}{$20-59$} \\
\hline Mean \pm SD of age & \multicolumn{2}{|c|}{$31.2 \pm 9.3$} \\
\hline \multicolumn{3}{|l|}{ Hospital } \\
\hline Port-Said general hospital. & 32 & 60.3 \\
\hline Elmabea health insurance hospital. & 15 & 28.4 \\
\hline Port -Fouad general hospital. & 6 & 11.3 \\
\hline \multicolumn{3}{|l|}{ Qualification } \\
\hline Diploma degree of nursing school. & 49 & 92.6 \\
\hline Bachelor degree & 4 & 7.5 \\
\hline \multicolumn{3}{|l|}{ Experience (years): } \\
\hline$<5$ years & 17 & 32.1 \\
\hline $5+$ years & 36 & 67.9 \\
\hline \multicolumn{3}{|l|}{ Attended training courses: } \\
\hline No & 30 & 56.6 \\
\hline Yes & 23 & 43.4 \\
\hline \multicolumn{3}{|l|}{ Worked abroad: } \\
\hline No & 50 & 94.3 \\
\hline Yes & 3 & 5.7 \\
\hline
\end{tabular}


Table (2):- Hemodialysis nurses total actual performance as regards hemodialysis standards of nursing care. $(N=53)$

\begin{tabular}{|c|c|c|c|c|}
\hline \multirow{3}{*}{ Items } & \multicolumn{4}{|c|}{ Total performance } \\
\hline & \multicolumn{2}{|c|}{$\begin{array}{l}\text { Adequate } \\
(60 \%+)\end{array}$} & \multicolumn{2}{|c|}{$\begin{array}{l}\text { inadequate } \\
(>60 \%)\end{array}$} \\
\hline & No & $(\%)$ & No & $(\%)$ \\
\hline Prepare equipment and supplies & 1 & 1.8 & 52 & 98.2 \\
\hline Attention to patient privacy and civil rights & & & 21.6 & 0 \\
\hline Protecting patient from accident/injury & 1 & 1.8 & 52 & 98.2 \\
\hline Attention to patient physical needs and comfort & 1 & 1.8 & 52 & 98.2 \\
\hline $\begin{array}{c}\text { Attention to patient psychological and } \\
\text { emotional needs }\end{array}$ & 0 & 0.0 & 53 & 100 \\
\hline Wearing masks & 0 & 0.0 & 53 & 100 \\
\hline Performing hand washing & 0 & 0.0 & 53 & 100 \\
\hline Wearing gown & 0 & 0.0 & 53 & 100 \\
\hline Wearing sterile gloves & 0 & 0.0 & 53 & 100 \\
\hline Preparing dress package & 0 & 0.0 & 53 & 100 \\
\hline Preparing dressing cart & 0 & 0.0 & 53 & 100 \\
\hline Preparing crush cart & 0 & 0.0 & 53 & 100 \\
\hline Assemble and setup machine: & 0 & 0.0 & 53 & 100 \\
\hline Read and check treatment plan & 0 & 0.0 & 53 & 100 \\
\hline Prepare machine & 1 & 1.8 & 52 & 98.2 \\
\hline Assess patient condition on admission & 0 & 0.0 & 53 & 100 \\
\hline Evaluate vascular access & 1 & 1.8 & 52 & 98.2 \\
\hline Access preparation/cannulation & 0 & 0.0 & 53 & 100 \\
\hline Initiate hemodialysis treatment & 1 & 1.8 & 52 & 98.2 \\
\hline Assessment and monitoring & 0 & 0.0 & 53 & 100 \\
\hline Termination of hemodialysis set: & 0 & 0.0 & 53 & 100 \\
\hline Patient: Prepare for ending the hemodialysis set & 1 & 1.8 & 52 & 98.2 \\
\hline Dialysis machine & 1 & 1.8 & 52 & 98.2 \\
\hline Environment & 1 & 1.8 & 52 & 98.2 \\
\hline Removing masking & 1 & 1.8 & 52 & 98.2 \\
\hline Removing gown & 0 & 0.0 & 53 & 100 \\
\hline Removing clean gloves & 0 & 0.0 & 53 & 100 \\
\hline Obtaining a blood sample & 1 & 1.8 & 52 & 98.2 \\
\hline Handling sharps & 0 & 0.0 & 53 & 100 \\
\hline Infection control measures & 1 & 1.8 & 52 & 98.2 \\
\hline Response to emergencies during hemodialysis: & 0 & 0.0 & 53 & 100 \\
\hline Patient & 0 & 0.0 & 53 & 100 \\
\hline Response to hypotension & 1 & 1.8 & 52 & 98.2 \\
\hline Response to other emergencies & 0 & 0.0 & 53 & 100 \\
\hline
\end{tabular}




\section{DISCUSSION}

The present study revealed that most of nursing staff providing direct patient care in all studied units are graduated from a diploma degree and a minority of them had baccalaureate degrees. Additionally all of them had more than 5 years experience in working in hemodialysis units and less than half of them had been joined trained courses regarding care of patient undergoing hemodialysis. Consists with this results the study of Abed Mowla (2012) who reported that nurses with baccalaureate degrees are restricted to administrative role.

As regards actual nurses performance to pre hemodialysis procedures, the findings of the present study showed that the majority of staff nurses did not perform the following procedures appropraitly; prepare equipment and supplies, prepare dressing package, prepare dressing cart, prepare the crush cart, ensure safe environment, ensure that infection control measures, assessment of patient's condition on admission, wear mask, hand wash, wear gown, wear sterile gloves and access preparation cannulation. This result may be due to lack of orientation program for new working nurses in the units, and lack of staff development program for hemodialysis nurses in the studied in hemodialysis units despite the presence of other instruments that were not used by hemodialysis staff e.g. package and basin. bedside shortage of nurses staff, shortage of equipments and needed supplies as masks, gowns, sterile dressings and instruments.

This result is in accordance with Mahmoud (2011) who found that hemodialysis unit did not include some resources likes mask, gown, sterile towel and sterile gauze pads. Additionally in the present study, it was observed that all the studied nurses did not perform hand washing before touching the patient, assessing patients' vital signs, assessing baseline fluid status, assessing laboratory results, or asking patients to evacuate the bladder before starting the procedure. However, a few nurses assessed patient weight, patient skin color and integrity, and mental status or recent changes in behavior. These findings may be due to the lack of nurses' knowledge about the importance of these actions and deficiencies in the documentation forms. Furthermore, the present study findings showed lack of hand washing, wearing personal protective clothes and review of the physician dialysis orders. These findings may be related to the environment factors as, absence of sinks 
inside patients' rooms to wash hands, lack of sterile gloves with different sizes to fit all the staff and other supplies for personal protection and documentation system in the unit does not support easy access to all dialysis orders.

As regards nurses' performance during hemodialysis, the present study found that, only a minority number of nurses performed assessment $\&$ monitoring patients during hemodialysis. These findings may be due to the lack of nurses' knowledge about the importance of these actions, shortage of nurses and not knowing how to assess the body systems.

This finding goes in line with Bin Salman (2009) who stated that the most important tasks/procedures of hemodialysis performed by nurses are assessment and monitoring patient and machine. These tasks include a series of continuously monitored data of the patient and machine before, during, and immediately after the hemodialysis procedure. On the other hand, the responsibility of reading, evaluating, and responding to this data, rely on the dialysis nurses. However, in the present study the nurses assessed vital signs and observed the patient only if he/she complained from any complication during hemodialysis, such as hypotension and muscle cramp to provide her/ him with suitable nursing intervention.

In relation to nurses' performance of post hemodialysis care, the present study findings showed that the nurses did not perform termination of a patient hemodialysis set, dialysis machine hemodialysis set, termination of environment hemodialysis set, removing the mask and removing sterile gloves. The present study results disagree with Richard (2011) who emphasized that after hemodialysis, the dialysis nurse should remove the needles from an AVF or AVG, apply manual pressure, and tape pressure dressings over the needle-skin entry sites. Additionally, the dialysis record will have the time that the last dose of anticoagulant was given, and the nurse can calculate the approximate time that its action will cease. Furthermore, nurses in the present study don't use aseptic technique during dressing and most of the nurses did not wash their hands or wear the sterile gloves. This finding contradicts Orlando Regional Healthcare (2005) who emphasized that vascular access sites must be handled with aseptic technique \& hand washing to prevent infection. Also, added standard nursing interventions should be applied to reduce infection risk in hemodialysis patients. (Orlando Regional Healthcare, Education and Development, 2005; Richard 2011). 
Moreover, the present study results revealed that almost all nurses ensure that patient has stable blood pressure, vascular access site without any complications, accumulated fluid was removed; dry weight restored and gradual performance of physical activity While, they did not ensure that the patient has stable health condition, BUN and creatinine restored to baseline levels and acid - base balance restored. The present finding is in agreement with Kallenbach et al. (2005) who stated that the hemodialysis nursing care outcome standard competency includes nursing evaluation of the body system for any abnormality, stable of vital signs, dry weight restored, gradual performance of physical activity and stable vascular access site without any complications. The finding is also supported by Van \& Micevski (2011) who described that the key component of nursing practice improvement involves continuous evaluation of performance to find ways to improve their role.

\section{CONCLUSION:}

\section{Based on study findings, it can be concluded that:}

1. Almost all nurses providing direct patient care in hemodialysis unit are graduated from a three years nursing school and have $<5$ years of experience.

2. Nurses holding a baccalaureate degree almost performed only administrative duties.

3. Almost all nurses working in the hemodialysis units had inadequate total performance.

4. Nurses working in the hemodialysis units had bad performance about hand washing, assessment and monitoring infection control measures.

\section{RECOMMENDATIONS:}

1. The developed standards of nursing care for management of patients undergoing hemodialysis should be available in Arabic and English language in all hemodialysis unit and should be revised and updated annually.

2. The developed standards of hemodialysis nursing interventions for management of patients undergoing hemodialysis should be included in the medical surgical course in the renal disorder unit.

3. Faculty of nursing should develop clinical training program about hemodialysis and its care including hemodialysis standards of care at regular basis to nurses working in the hemodialysis unit and should be made on nurse's free days so that these programs don't interfere with nurse's clinical work schedule and each one is able to attend these programs. 
4. The educational institutes should collaborate with the staff of hemodialysis units in formulating policies, procedure manuals, guidelines, protocols and job description.

5. Providing the working nurses with continuing education and in-service education training program about hemodialysis and its management including the standards of nursing care pre, during and post.

\section{REFERENCES}

Abed Mowla, H. and Ahmed (2012): Developing nursing interventions standAards for patients undergoing thoracic surgeries. Unpublished doctoral thesis. Faculty of Nursing, Alexandria University.

Bin Salman, F. and Charity (2009): Clinical Practice Measures for Hemodialysis Centers in Saudi Arabia. Riyadh, King Fahad National Library Cataloging-in-Publication Data, available at: www.fahadkella.org.sa, accessed in 7-7-2012

Castner, D. (2011): Management of patients on hemodialysis before, during, and after hospitalization: Challenges and suggestions for improvements. Nephrology Nursing Journal, 38(4): 319-330.

Dewit, S. and Kumagai, C. (2013): Medical-surgical nursing concepts \& practice 2nd ed. WB Saunders, an imprint of Elsevier Inc. printed in the United States of America; P.p. 798-817.

Ignatavicius, D.I. and Workman, M.L. (2010): Medical-surgical nursing: patient-centered collaborative care. 6th ed., WB Saunders an imprint of Elsevier Inc. USA, P.p. 1175-1190.

Kallenbach, J.Z., Gutch, C.F., Stoner, M.H. and Corea, A.L. (2005): Review of hemodialysis for nurses and dialysis personnel. 7th ed., Elsevier Mosby Inc., USA, P. 3, 1-10, 146-153, 314,

Mahmoud, H.H.F. (2011): Implementing a Developed Nursing Care Standards for Hemodialysis Patients In Zagazig University Hospital, Unpublished doctoral thesis. Faculty of Nursing, Zagazig University. 
Orlando Regional Healthcare, Education and Development. (2005): Principles of Continuous Renal Replacement Therapy Self-Learning Packet, Elsevier Mosby Inc., P.p23.

Richard, C. (2011): Preservation of Vascular Access for Hemodialysis in Acute Care Settings. Wolters Kluwer Health. Lippincott Williams \& Wilkins. Unauthorized reproduction of this article is prohibited. P.p 76-83.

Van Soeren, H. and Micevski, V. (2011): Success indicator and barriers to acute nurse practitioner role implementation in four Ontario hospitals. American Association for Critical-Care nursing (AACN) clinical Issues. 12(4)220-235

Zahran, A. (2011): Epidemiology of hemodialysis patients in Menofia governorate, Delta region, Egypt Menoufiya Medical Journal. 24(2): 59-70. 


\section{تقييم مهارات الممرضات للأستصفاء الاموي

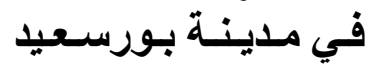

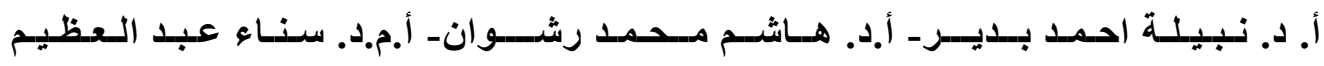

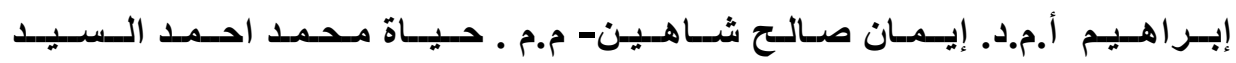

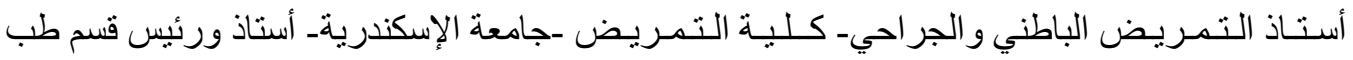

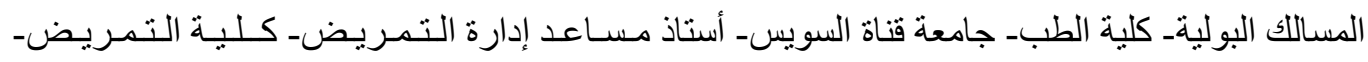

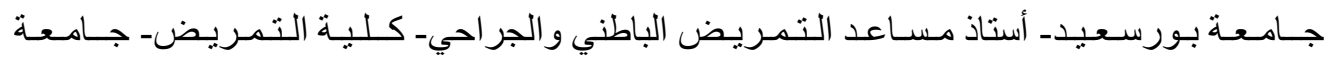

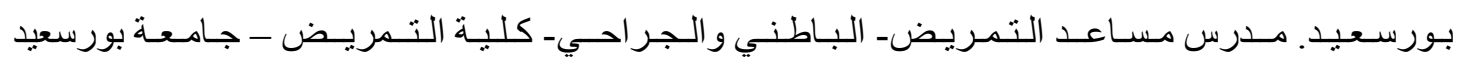

\section{الــــلاصـــة}

أصبحت المر احل الأخيرة للفثل الكلوي مصدر قلق للصحة العامة في جميع أنحاء العالم كذلك إن الفثل الكلوي بمراحله الأخيرة يتطلب العلاج المنزايد بشكل كبير، في مصر، هناك أيضا زيادة في انتشار وحدوث أمراض الكلي بمر احلها الأخيرة ويشكل ذلك عبئا كبير ا على نظام الرعاية الصحية في مصر.

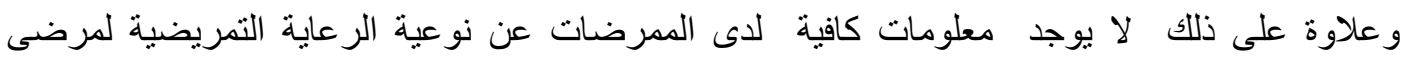
الأستصفاء الدموي. وتهدف الدراسة إلى إعداد معيار للرعاية التمريضية لمرضى الأستصفاء الدموي في لهي مستشفى بورسعيد العام و بورفؤاد العام والمبرة ـ وأجريت الدراسة في وحدات الأستصفاء الدموي ببورسعيد. وقد اشتملت عينة البحث على (53) ممرضها تقدم الرعاية التمريضية. و استخدمت لملاحظة لتقييم

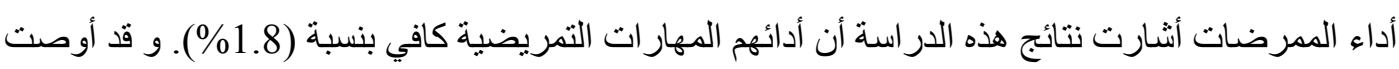
هذه الدر اسة بضرورة وضع معايير للعناية التمريضية لمرضى الأستصفاء الدموي ويجب أن تكون منوفرة بعدد كافي بوحدة الأستصفاء الدموي باللغة العربية والانجليزية وتكون محدثه سنويا. الكلمات الإسترشادية : تقييم ، مهارات ، الممرضات، للأستصفاء الدموي 